\title{
THE ACTION OF HISTAMINE ON THE PANCREAS
}

\author{
By A. V. NEALE ${ }^{1}$ AND T. G. KLUMPP
}

(From the Infants' and Children's Bospital, and the Department of Pediatrics, Harvard Medical School, Boston)

(Received for publication May 5, 1930)

Claude Bernard (1856) and Heidenheim (1883) in their general physiological studies, initiated the earliest ideas of pancreatic function, but it remained for the classical experimental work of Pawlow (1901) and Bayliss and Starling (1902) to demonstrate the fundamental concepts of the physiology of the pancreas as a gland of external secretion. Pawlow observed that a flow of pancreatic juice occurred after the entry of the chyme into the duodenum. He suggested that this effect was due entirely to reflex vagal activity and supported this idea by obtaining a secretion on directly stimulating the vagi. That this was not the whole truth was shown by the experimental studies of Bayliss and Starling (1) in which it was indicated that pancreatic secretion could also be initiated by the contact of the duodenal mucosa with a weak acid solution, or by the injection of an extract of the mucosa itself; this whole phenomenon being due to the elaboration and circulation of a chemical stimulant of hormonic qualities. After extensive experiments these workers established the specificity of this hormonic stimulation, and noted the absence of any action on the salivary and gastric glands. This humoral theory was amply supported by Farrell and Ivy (2) who obtained active and copious secretions in a denervated transplanted portion of the pancreas after the ingestion of a meal. This transplant also yielded a small continuous resting secretion containing the digestive enzymes.

That the two methods of pancreatic stimulation induce secretions differing in composition is now well known,-- "vagal" juice being small in volume but rich in protein and enzymes, - while "secretin" juice is copious in quantity, poor in proteins and enzymes but definitely alkaline due to the carbonate content. Atropine paralyzes the vagal

${ }^{1}$ Rockefeller Fellow in Pediatrics. 
stimulation but does not affect the secretin response. Pilocarpine on the other hand causes an elevation in the enzymes secreted. Babkin (3) had shown that the zymogen granules in the pancreatic acinar cells greatly diminish after vagal stimulation. Under normal conditions, therefore, there appears to be a dual and yet coördinated activity of the two types of pancreatic stimuli. In the presence of achlorhydria, the action of secretin is probably negligible and vagal juice plays a dominant rôle in pancreatic digestion. The production of a copious flow of dilute bicarbonate solution may not be essential to normal digestion, although its main function would appear to ensure, in the presence of an acid chyme, an optimal reaction in the chyle for the maximal activity of the pancreatic digestive enzymes. A number of our investigations suggest that the achylia of pernicious anemia in no way impedes the secretion, or the activity of the pancreatic ferments. It is likely that this secretion is due to vagal stimulation and that the hormonic activity in complete achylia is slight or absent since the secretion is practically abolished by atropine. It is noteworthy that the flow of dilute bicarbonate solution which is probably the response to hormonic activity, is not present in achylia where alkalinization of the gastric contents is unnecessary. It is interesting that enzyme production and hydrogen ion concentration, the regulation of which is so important for intestinal digestion, should be separately initiated.

\section{HISTAMINE}

Histamine, when injected subcutaneously, stimulates the secretion of gastric juice. Cushny (4) remarks that this substance also stimulates pancreatic secretion, although a careful search through the literature has failed to produce any experimental data to corroborate this statement. It was this note in Cushny's book which gave the writers a desire to investigate the action of histamine on the pancreas. It was thought possible that a method of studying pancreatic function might be established if it could be definitely demonstrated that histamine stimulates the pancreas as it does the gastric glands. With this object an experimental method was devised to determine whether histamine, on subcutaneous injection, would increase the volume of pancreatic secretion or the concentration of enzyme therein. 
All the experiments have been carried out in normal healthy children ranging in age from six weeks to twelve years. Children were used for the experimental work because it was also desired to obtain collateral data on the enzyme and volumetric secretion at various ages during childhood. Again, for many reasons, the most important being the considerable length of the experiments in some instances, children were found to be more suitable than adults. A few observations on adults have been made.

\section{METHOD}

A quiet and coöperative patient was essential; the child lying down in bed inclined toward the right side. An interval of about six hours was allowed after the last meal; an early breakfast was given, and the experiment commenced in the forenoon. A special small torpedo shaped aspirating tip, capable of passing through the nose of the smallest infant, and yet heavy enough to be influenced in the stomach by gravity, was devised. This will be described in a clinical note. The tip, at the end of a fairly stiff rubber tubing, was introduced into the duodenum, and its position verified by fluoroscopic examination. It was left in place throughout the experiment; so long as the child remained fairly quiet no displacement occurred. Constant drainage of the duodenal contents was maintained, and the amount of secretion measured every ten or fifteen minutes. Obviously, uninterrupted supervision of the child was required throughout the experiment to aspirate and collect the fluid, and to eliminate all extrinsic inhibitory or disturbing factors.

The passage of gastric juice into the duodenum could be readily detected by the change in appearance of the aspirate. All fractional samples of fluid obtained were verified by determination of the $\mathrm{pH}-$ colorimetrically after dialysis, according to the method described by Marriott and Davidson (7).

In order to determine the gastric secretory response to the same dose of histamine, a separate experiment was carried out on the day following the pancreatic experiment. One of us (A. V. N.) has already reported upon the dosage of histamine ("Imido-Roche"), for children of different age groups, which causes a maximal flow of acid gastric juice (6). 
The concentration of enzymes in the duodenal fluid was determined by the methods of McClure, Wetmore and Reynolds (5).

\section{- RESULTS}

After preliminary experiments, a standard procedure was developed. Some thirty subjects were investigated with very satisfactory and uniform results. Only a few of these experiments are shown in the charts but they are typical examples of the findings in all.

On charts A and B the gastric and duodenal response to an injection of histamine in two typical cases are presented. They show that within a few minutes (15 to 45 minutes) after the injection, the gastric secretion is stimulated whereas the duodenal flow is simultaneously diminished. The gastric and duodenal secretions are apparently inversely affected. As the histamine effect disappears the gastric secretion falls and the duodenal secretion tends to return to its previous resting level. The enzyme content in the pancreatic secretion also shows a corresponding lack of stimulation or even a fall. These findings were typical of those obtained in all the experiments.

Charts C, D and E depict the same findings as charts A and B; but in addition there is shown the stimulation of the pancreas after the histamine action has ceased, by the entrance of gastric secretion into the duodenum. The upper line on the graphs shows the $\mathrm{pH}$ of the fluid collected at the corresponding times in the duodenum. In all instances, the reaction obtained confirmed our interpretation as to the nature of the fluid collected. It will be noticed that there is a slight alkaline "tide" in the duodenum coincident with the phase of histamine activity during which there is a large outpouring of acid gastric secretion into the stomach.

It is interesting to note that following the entrance of the acid gastric contents into the duodenum, the pancreatic flow which follows is profuse, watery, and alkaline, ("secretin juice"). In chart $\mathrm{C}$ this is shown very well, the secretion reaching a rate of 240 cubic centimeters per hour. In one case it rose to 300 cubic centimeters per hour. After cessation of the acid stimulation, the rate of secretion again falls to the resting level of the individual concerned.

Table 1 shows the rate of secretion into the duodenum and its reaction during the pre- and post-histamine phases. In each case the rate 


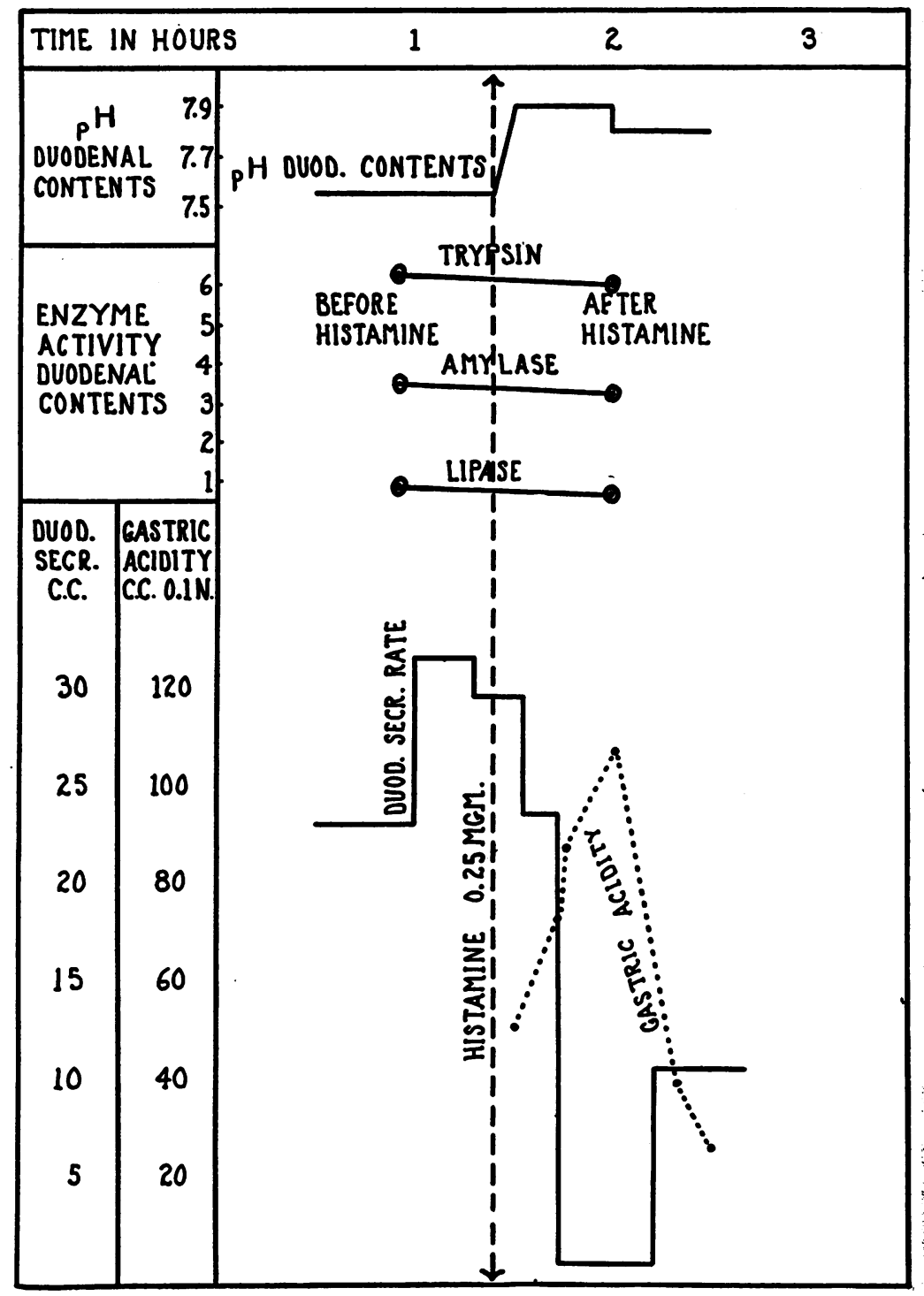

Chart A. Gastric and Duodenal Response to Histamine. R. N. 9 Years 6 MONTHS 


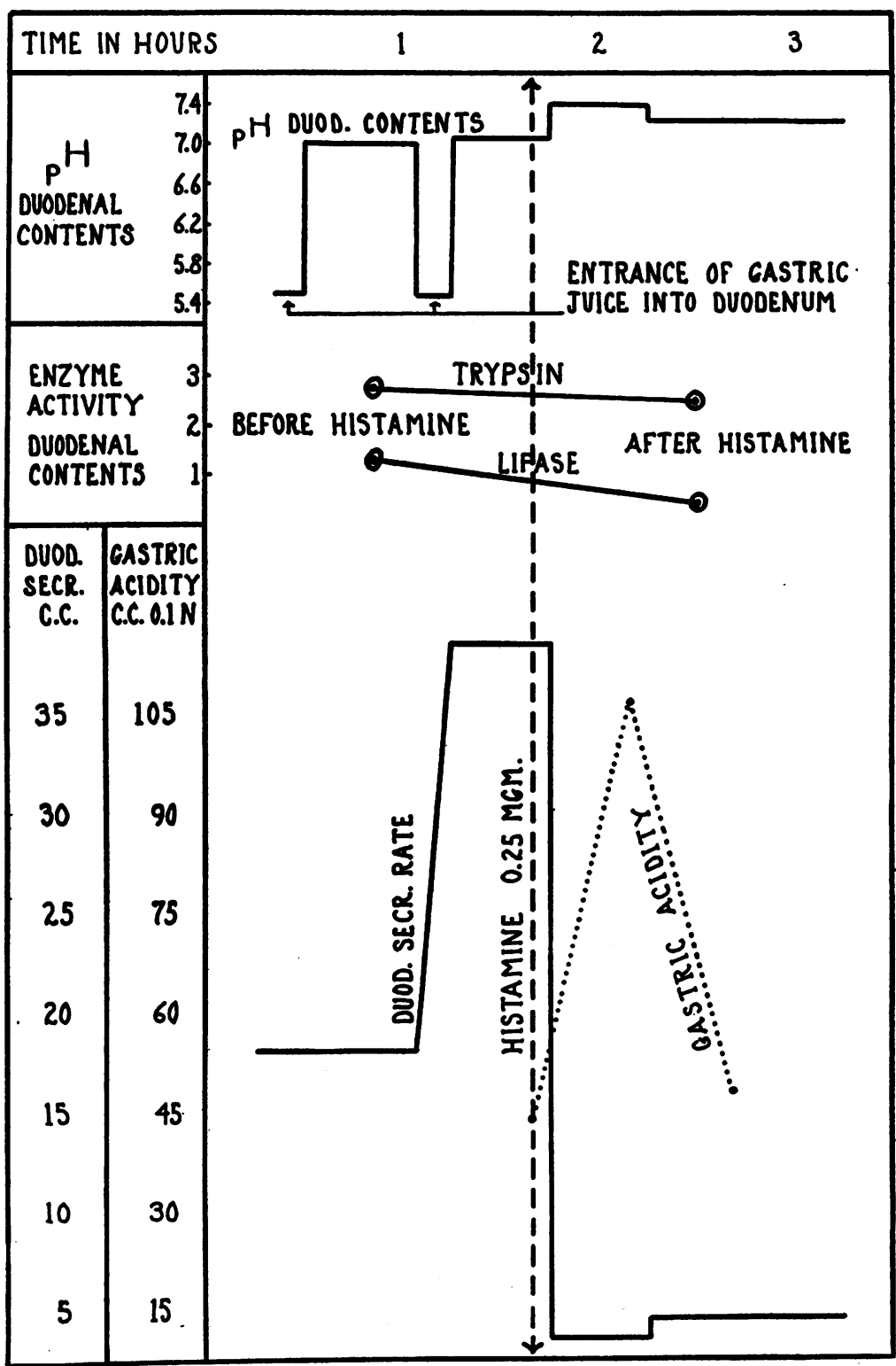

Chart B. Gastric and Duodenal Response to Histamme. E. S. 9 Years, 11 MoNTHS 


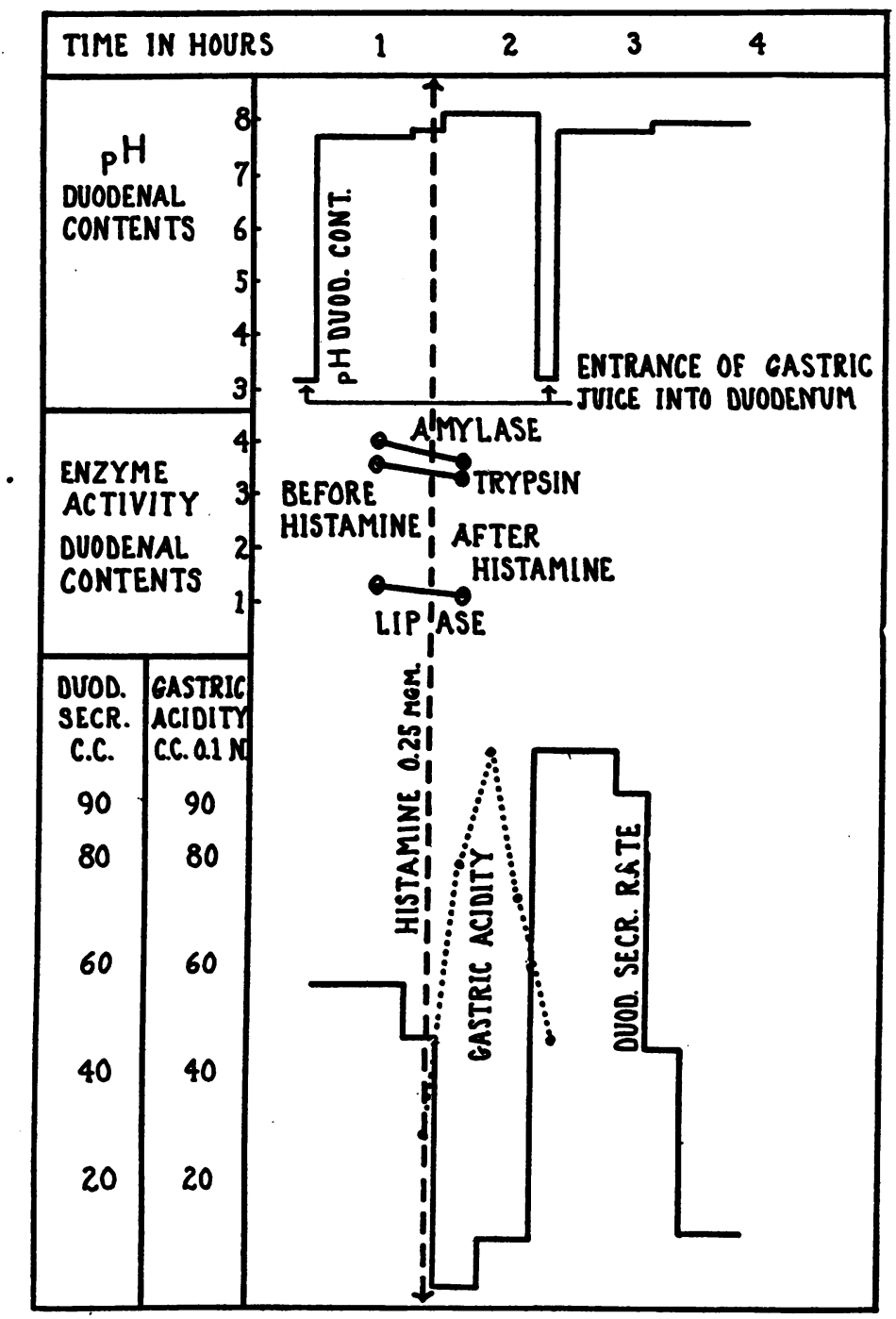

Chart C. Gastric and Duodenal Response to Histamine. J. C. 7.6/12 Years 


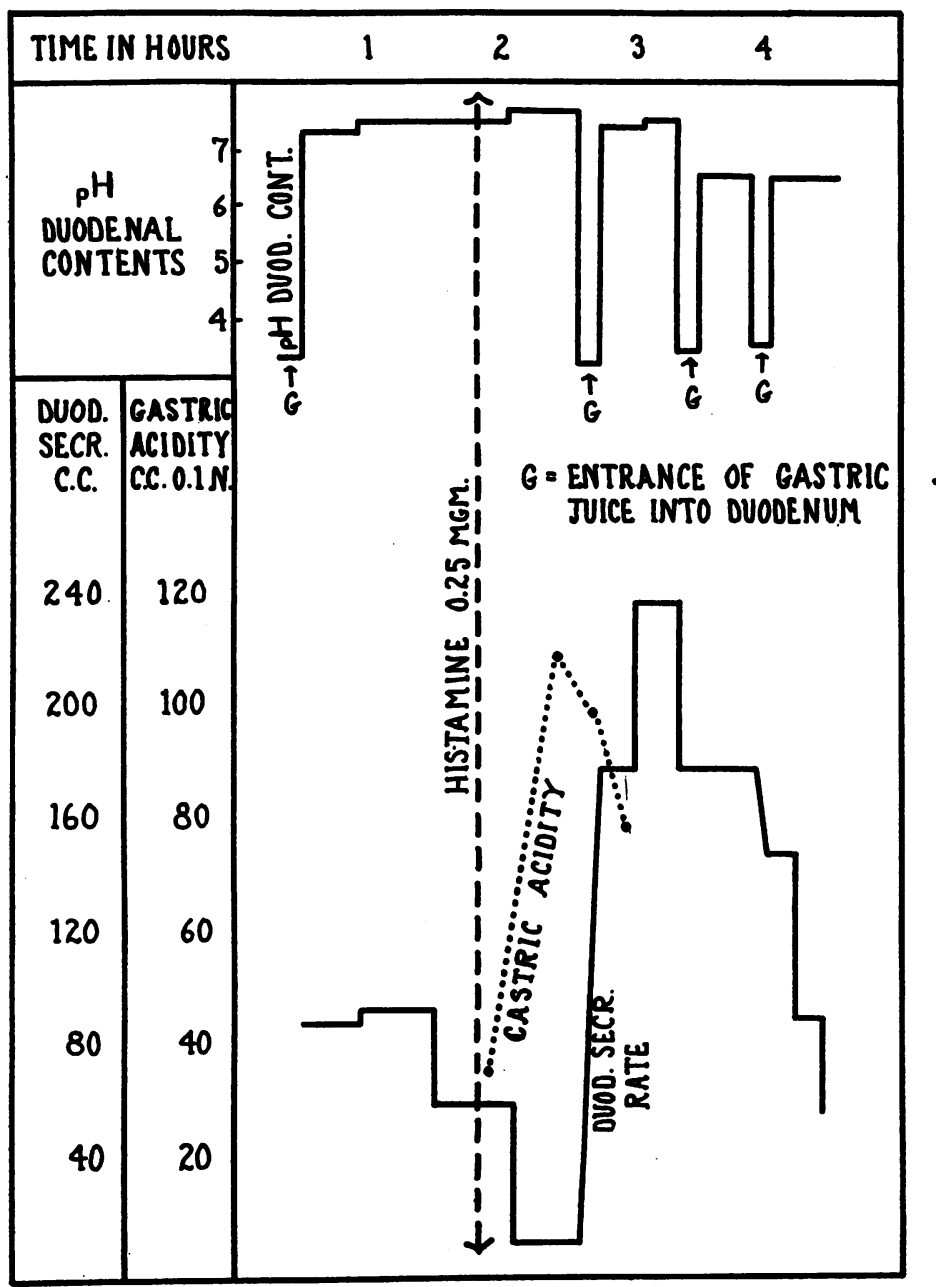

Chart D. Gastric and Duodenal Response to Histamine. M. J. 12 Years 


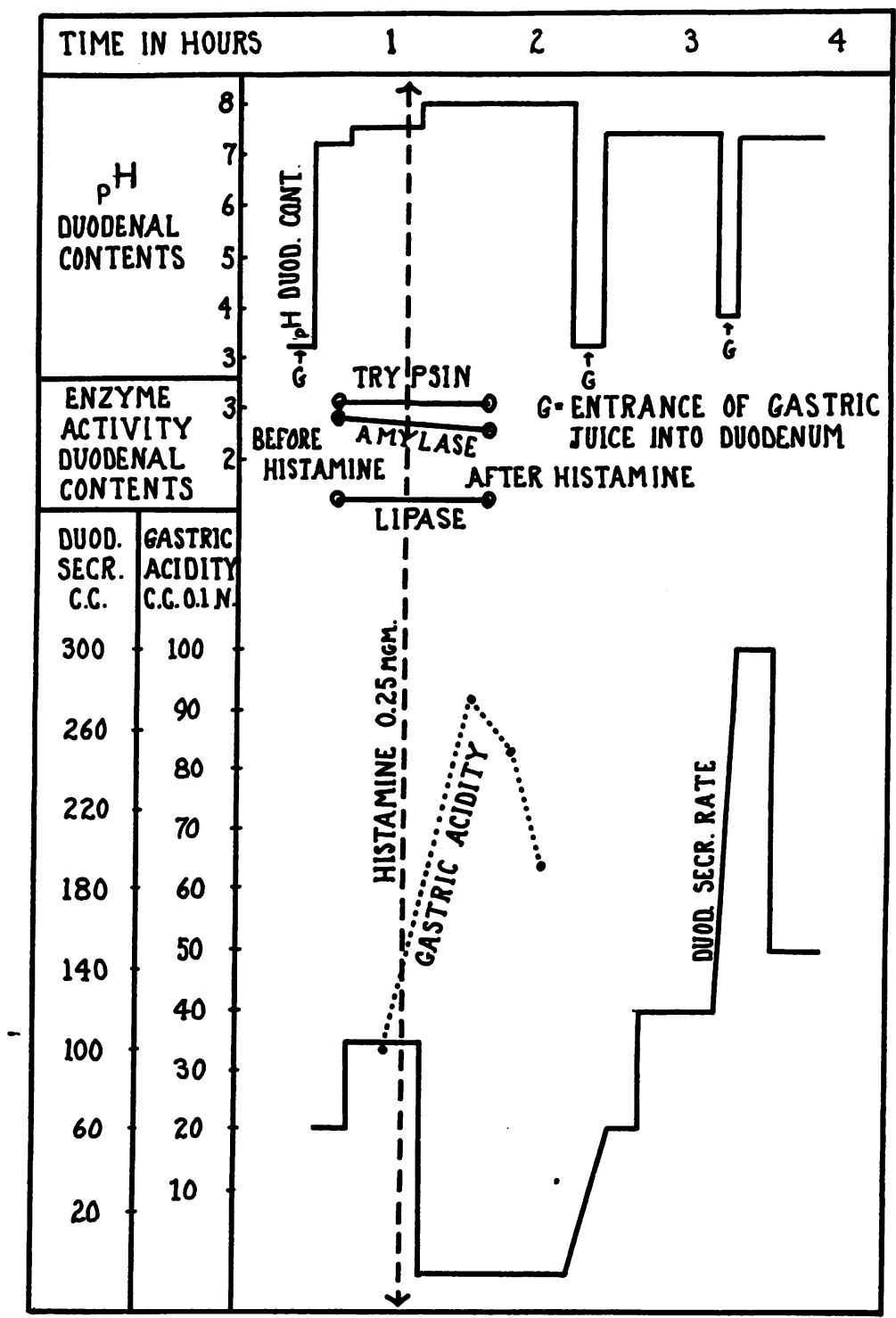

Chart E. Gastric and Duodenal Response to Histamine. A. S. 11 Years 
TABLE 1

Rate of secretion and $p H$ of the duodenal contents before and after histamine

\begin{tabular}{|c|c|c|c|c|c|c|}
\hline \multirow{2}{*}{ Case } & \multirow{2}{*}{\multicolumn{2}{|c|}{ Age }} & \multicolumn{2}{|c|}{ Before histamine } & \multicolumn{2}{|c|}{ After histamine } \\
\hline & & & $\begin{array}{c}\text { Rate of secre- } \\
\text { tion }\end{array}$ & $\mathrm{pH}$ & $\begin{array}{c}\text { Rate of secre- } \\
\text { tion }\end{array}$ & pH \\
\hline & yrs. & mos. roks. & cc. per hour & & cc. per hour & \\
\hline B. C.............. & & 6 & 3 & 7.3 & 1 & 7.6 \\
\hline B. M........... & & 4 & 8 & 7.2 & 5 & 7.4 \\
\hline R. H.............. & & 9 & 4 & 7.4 & 1.5 & 7.5 \\
\hline J. G............ & & 10 & 4 & 7.5 & 2 & 7.6 \\
\hline R. M............. & 1 & & 12 & 7.4 & 3 & 7.8 \\
\hline A. L.......... & 7 & & 40 & 7.4 & 4 & 7.8 \\
\hline J. C. . . . . . & 7 & 6 & 60 & 7.8 & 6 & 8.2 \\
\hline I. D............... & 7 & 10 & 60 & 7.3 & 12 & 7.5 \\
\hline F.A.......... & 9 & 4 & 70 & 7.2 & 7 & 7.5 \\
\hline A. $\mathrm{K} . . . \ldots$. & 9 & 5 & 80 & 7.3 & 20 & 7.6 \\
\hline R. N............... & 9 & 6 & 30 & 7.2 & 9 & 8.0 \\
\hline E. T............. & 9 & 7 & 35 & 7.2 & 3 & 8.2 \\
\hline A. V........... & 9 & 10 & 54 & 7.4 & 6 & 7.6 \\
\hline A. S............. & 10 & 10 & 128 & 7.4 & 18 & 7.4 \\
\hline M. J............. & 11 & 8 & 90 & 7.6 & 20 & 7.6 \\
\hline
\end{tabular}

TABLE 2

Enzyme activity of duodenal contents before and after histamine

\begin{tabular}{|c|c|c|c|c|c|c|c|c|c|}
\hline \multirow{3}{*}{ Case } & \multirow{3}{*}{\multicolumn{3}{|c|}{ Age }} & \multirow{2}{*}{\multicolumn{2}{|c|}{$\frac{\text { Amylase }}{\text { Mgm. glucose }}$}} & \multirow{2}{*}{\multicolumn{2}{|c|}{$\frac{\text { Trypsin }}{\text { Mgm. N.P.N. }}$}} & \multirow{2}{*}{\multicolumn{2}{|c|}{$\frac{\text { Lipase }}{\text { Cc. } 0.1 \times \mathrm{NaOH}}$}} \\
\hline & & & & & & & & & \\
\hline & & & & Before & After & Before & After & Before & After \\
\hline & yrs. & mos. & wks. & & & & & & \\
\hline B. C..... & & & 6 & 0.6 & 0.2 & 1.2 & 1.2 & 0.5 & 0.2 \\
\hline B. M. . . . . . . & & 4 & & 0.2 & 0.2 & 2.3 & 2.3 & 0.8 & 0.7 \\
\hline R. H............ & & 9 & & 0.4 & 0.2 & 0.7 & 0.7 & 0.2 & 0.2 \\
\hline B. G............ & & 10 & & 1.8 & 0.8 & 2.0 & 1.8 & 0.6 & 0.5 \\
\hline R. M........... & 1 & & & 1.6 & 1.2 & 1.7 & 2.0 & 1.3 & 1.3 \\
\hline J. C........ & 7 & 6 & • & 3.1 & 3.0 & 3.7 & 3.5 & 1.0 & 1.1 \\
\hline R. N........... & 9 & 6 & & 3.4 & 3.3 & 6.1 & 6.0 & 0.5 & 0.5 \\
\hline E. S............ & 9 & 11 & & & & 2.2 & 2.2 & 1.1 & 0.9 \\
\hline
\end{tabular}

of secretion fell and a change towards greater alkalinity occurred after histamine had been given. This may be a mechanism to compensate for the large amount of acid mobilized from the internal environment 
into the stomach. These effects are seen to occur in the whole series here shown-aged six weeks to nearly twelve years.

Table 2 shows the numerical concentration of the three pancreatic enzymes before and after injecting histamine. Here again there is no evidence of stimulation, each enzyme showing either no change, or a decrease in activity.

\section{DISCUSSION}

From the results obtained in our own experiments, as well as those of others, there is no doubt that histamine is a specific stimulant to the gastric secretory mechanism. That this action is very probably a direct one on the glands is suggested by the absence of any modifying effect by atropine during the experiment.

We expected, from Cushny's statement that histamine would act on the pancreas in a way similar to its action on the gastric glands, and might be used similarly as a method of testing pancreatic function or capacity. The results reported in this paper show that no such effect is obtained. Histamine appears to have no stimulative action whatever on the pancreas. In fact there is a diminution in the normal "resting" secretion of the gland following the injection of an adequate dose of histamine. This failure to promote pancreatic secretion includes both volume of pancreatic flow and enzyme content. Any duodenal fluid collected during the period of histamine action is more alkaline than before or afterwards, this being due apparently to a compensatory secretion of alkali into the duodenum during the secretion of acid into the stomach. We have also noticed that histamine does not appear to cause any increase in salivary secretion when all measures are taken to eliminate mechanical stimulation of the mouth or throat.

It is a remarkable fact that histamine acts so specifically upon the gastric glands and fails to promote secretion in other glands concerned with alimentation and digestion. This specificity suggests a close analogy between the physiological properties of histamine of the hormones in the body.

\section{CONCLUSIONS}

1. The action of histamine on the pancreatic secretions into the duodenum in children of different ages has been investigated. 
2. Histamine caused no increase of either the volume of pancreatic secretion or of its enzyme activity.

3. An increase in the alkalinity of the duodenal contents (alkaline tide) accompanied the secretion of acid into the stomach in response to histamine.

\section{BIBLIOGRAPHY}

1. Bayliss, W. M., and Starling, E. H., J. Physiol., 1902, xxviii, 325. The Mechanism of Pancreatic Secretion.

2. Farrell, J. I., and Ivy, A. C., Am. J. Physiol., 1926, Ixxviii, 325. Contributions to the Physiology of the Pancrease. II. The Proof of a Humoral Mechanism for External Pancreatic Secretion.

3. Babkin, B. P., Rubaschkin, W. J., and Ssawitsch, W. W., Arch. mikr. Anat., 1909, lxxiv, 68. Uber die morphologischen Veränderung der Pankreaszellen unter der Einwirkung verschiedenartiger Reize.

4. Cushny, A. R., Text Book of Pharmacology and Therapeutics. Lea and Febiger, Philadelphia, 1928, 9th ed., p. 410.

5. McClure, C. W., Wetmore, A. S., and Reynolds, L., Arch. Int. Med., 1921, xxvii, 706. New Methods for Estimating Enzymatic Activities of Duodenal Contents of Normal Man.

6. Neale, A. V., Arch. Dis. Child. London-To be published.

7. Marriott, W. McK., and Davidson, L. T., Am. J. Dis. Child., 1923, xxvi, 542. The Acidity of the Gastric Contents of Infants. 